Arq. Bras. Med.Vet. Zootec., v.69, n.5, p.1145-1151, 2017

\title{
Tumor da célula da granulosa associado à piometra em uma gata de sete meses
}

\author{
[Granulosa-cell tumor associated with pyometra in a seven months old cat] \\ A.D.P. Sampaio, R.F. Bittencourt*, L.P. Maggitti Júnior, E.S. Santos, M.A.A. Silva, \\ E.L.T. Moreira, M.C.C. Lima \\ Universidade Federal da Bahia - UFBA - Salvador, BA
}

\section{RESUMO}

As neoplasias ovarianas em gatas são raras e, quando relatadas, estão associadas a animais senis, assim como a piometra de causa não iatrogênica. O objetivo deste trabalho foi relatar o caso de uma gata jovem com neoplasia ovariana, tumor de células da granulosa associado ao complexo hiperplasia endometrial cística/piometra (HECP). O animal foi atendido no setor de Reprodução Animal e Obstetrícia Veterinária (RAOV) de um Hospital Veterinário Escola, com histórico de monta natural recente, anorexia, êmese, polidipsia, poliúria e descarga vaginal purulenta. Ao exame físico, observou-se apatia, mucosas ictéricas, aumento de volume da região abdominal e presença de secreção vaginal purulenta. À ultrassonografia, foi visibilizado conteúdo ecogênico no útero diagnóstico de HECP e estrutura ecogênica na cavidade abdominal, na região ovariana, confirmado pelo exame histopatológico como sendo tumor das células da granulosa. A conduta terapêutica adotada foi a cirurgia de ovariossalpingo-histerectomia (OSH).

Palavras-chave: felino, tumor da granulosa, HECP, neoplasia, ovário

\begin{abstract}
Ovarian neoplasias in cats are rare, and are associated with advanced ages, as well as non-iatrogenic pyometra. The objective of the present study was to report a case of a young cat showing signs of a rare neoplasia, the granulosa-cell tumor, associated with complex cystic endometrial hyperplasia/pyometra (HECP). The animal was attended in the Animal Reproduction and Veterinary Obstetrics sector of a Teaching Veterinary Hospital with a history of natural breeding, anorexia, emesis, polydipsia, polyuria, and purulent vaginal discharge. During clinical examination, apathy, icterus, swelling of the abdomen, and purulent vaginal discharge were observed. On the ultrasonographic exam, an echogenic content inside the uterus was observed, leading to diagnosis of HECP and an echogenic structure in the abdominal cavity, in ovarian region, confirmed by histopathology as being of granulosa cells. The therapeutic conduct adopted was salpingo-oophorectomy and hysterectomy surgery $(\mathrm{OSH})$.
\end{abstract}

Keywords: feline, granulosa-cell tumor, HECP, neoplasia, ovary

\section{INTRODUÇÃO}

A liberação endógena ou exógena de forma mais prolongada dos hormônios sexuais promove modificações no ambiente uterino. A hiperplasia endometrial cística (HEC) é uma alteração do endométrio uterino de cadelas e gatas, que está associada aos hormônios estrógeno e progesterona (Sousa Oliveira, 2007).
A HEC mediada pelo estímulo da progesterona se dá por meio de diversas alterações uterinas, tais como a proliferação endometrial, a secreção glandular e a diminuição da contratilidade miometrial. Esses eventos se acentuam se houver uma exposição muito prolongada a progestágenos após altos níveis plasmáticos de estrógeno circulante, criando-se ambiente favorável ao crescimento bacteriano (Sousa Oliveira, 2007; Barni et al., 2013).

Recebido em 8 de novembro de 2016

Aceito em 3 de dezembro de 2016

*Autor para correspondência (corresponding author)

E-mail: rfb@ufba.br 
Assim, o complexo HEC/piometra de estímulo hormonal endógeno é menos prevalente em gatas, já que necessita do coito para que ocorra a ovulação e posteriormente o desenvolvimento do corpo lúteo e a subsequente liberação de progesterona (Martins, 2007). Entretanto, a HEC intercedida pela estimulação do estrógeno de forma não cíclica e prolongada ocorre devido às modificações inerentes ao ovário, como cistos foliculares e o tumor de células da granulosa, caracterizando-se pela hipertrofia do miométrio e hiperplasia do endométrio (Santos e Alessi, 2011).

Os tumores ovarianos são raros em cães e gatos; nos felinos, variam de 0,7 a $3,6 \%$ de todas as neoplasias observadas. Entretanto, o tumor de células da granulosa, dentre os ovarianos, é o de maior prevalência. A faixa etária de animais acometidos está entre dois e 10 anos (Daleck et al., 2009). Esse tipo de tumor pode acometer animais castrados, nos quais, por falha na técnica cirúrgica, o tecido ovariano não tenha sido removido completamente e, por conseguinte, tenha se desenvolvido a síndrome do ovário remanescente (Souza et al., 2005).

O tumor de células da granulosa pode acometer diversas espécies domésticas, bovinos, equinos, caninos e felinos. Caracteriza-se por um aumento nos níveis plasmáticos de hormônios sexuais, e tanto as cadelas como as gatas respondem com elevadas concentrações de estrógeno (Daleck et al., 2009; Santos e Alessi, 2011).

O diagnóstico pode ser sugerido com base no histórico do animal e em ultrassonografia, mas não é irrefutável. A citologia aspirativa não é recomendada. A radiografia pode ser usada para verificar a presença de metástases; caso não haja e o prognóstico, portanto, seja favorável, o tratamento de eleição é a ovariossalpingohisterectomia terapêutica. $\mathrm{O}$ diagnóstico conclusivo do tumor das células da granulosa é obtido pelo exame histopatológico (Giacóia et al., 1999; Souza et al., 2005; Daleck et al., 2009; Scucato, 2009).

O objetivo do presente trabalho foi relatar o caso de uma gata de sete meses com neoplasia ovariana, tumor de células da granulosa associado à piometra.

\section{CASUÍSTICA}

Uma gata, SRD, sete meses, pelagem branca, foi atendida no Setor de Reprodução Animal e Obstetrícia Veterinária de um Hospital Veterinário Escola, com histórico de secreção vaginal após ter sido coberta no primeiro estro, mucosas ictéricas, polidipsia, poliúria, êmese e anorexia havia uma semana. O proprietário trouxe laudo ultrassonográfico com diagnóstico de piometra e terapia antibiótica prévia com cefalosporina (cefalexina) e nitroimidazólico (metronidazol). A gata estava com as vacinas e o vermífugo em dia, bem como o gato contactante, e alimentava-se somente de ração classificada como super premium.

Ao exame físico, o animal apresentava-se apático, desidratado, com mucosas ictéricas, frequência cardíaca de 160 batimentos por minuto, pulso sincrônico, frequência respiratória de 40 movimentos por minuto, auscultação cardiopulmonar clara e limpa, tempo de preenchimento capilar menor que três segundos, linfonodos não reativos e temperatura de $37,3^{\circ} \mathrm{C}$. $\mathrm{Na}$ palpação abdominal, verificou-se um aumento na região e, na inspeção vulvar, notouse presença de exsudato purulento vaginal.

Como exame complementar para diagnóstico, foi realizada ultrassonografia abdominal (Z5, Mindray, transdutor convexo, frequência de $5 \mathrm{MHz}$ ), na qual se observou o útero com aumento de suas dimensões, hiperplasia endometrial e presença de conteúdo ecogênico. Visibilizou-se ainda estrutura hiperecogênica na região abdominal, com aproximadamente $3,5 \mathrm{~cm}$ de diâmetro, e regiões com presença de conteúdo hipoecoico (Fig. 1, 2 e 3).

Quanto aos parâmetros sanguíneos e sistêmicos, estes foram obtidos por meio do eritrograma e do leucograma, além de parâmetros bioquímicos. No eritrograma, verificou-se alteração do volume globular com 36,9fL e leucograma com neutrofilia de $12.220,0 \mu \mathrm{L}$. 


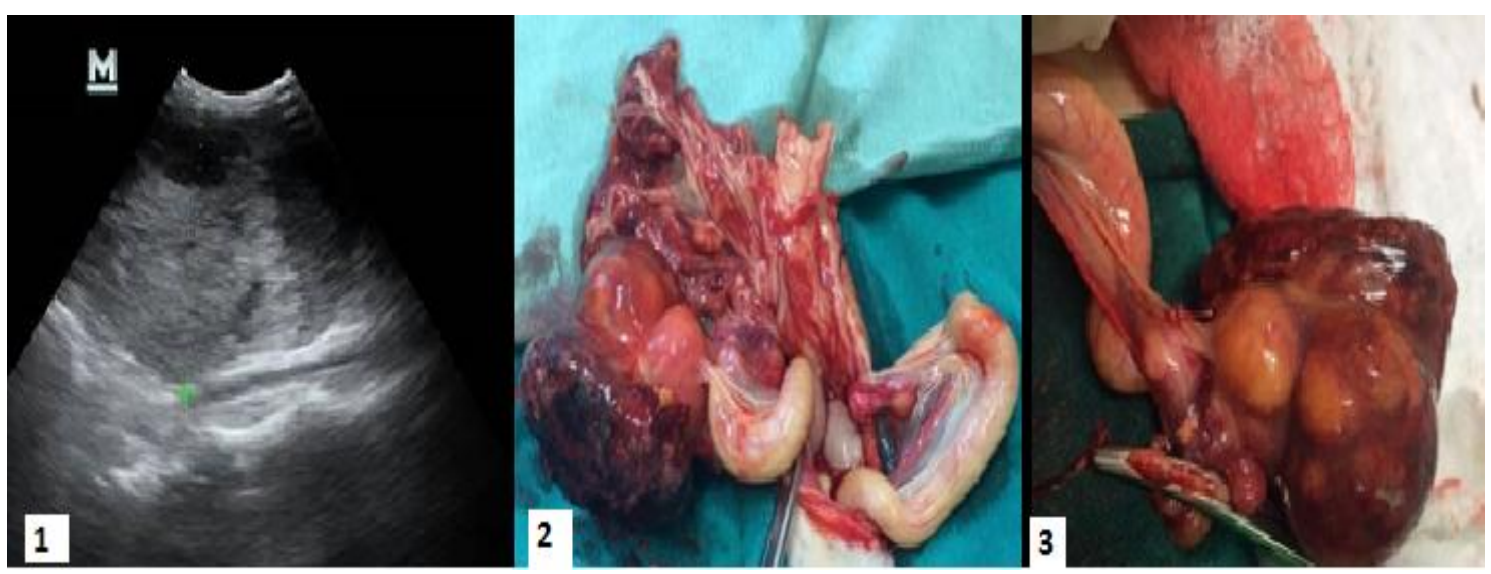

Figura 1. Imagem ultrassonográfica de massa ecogênica na cavidade abdominal em região de ovário de uma gata de sete meses com tumor da célula da granulosa. Figura 2. Exposição do ovário acometido com a neoformação e do útero com aumento de volume. Figura 3. Ovário evidenciando o tumor de células da granulosa.

Os demais parâmetros hematológicos encontravam-se dentro da normalidade para a espécie: hemácias 5,9 (x $\left.10^{6} \mu \mathrm{L}\right)$, hemoglobina $7,3 \mathrm{~g} / \mathrm{dL}$, volume globular $21,8(\%)$, volume globular médio 36,9 (fL), concentração de hemoglobina corpuscular média 33,5 (\%), plaquetas $166.000 \mu \mathrm{L}$, metarrubrícitos 0,0 (/100 Le) e proteína total (plasma) $6,0 \mathrm{~g} / \mathrm{dL}$. No leucograma, observaram-se leucócitos totais com $13.000 \mu \mathrm{L}$, mielócitos $0,0 \mu \mathrm{L}$, metamielócitos $0 \mu \mathrm{L}, \quad$ segmentados $12.220,0 \mu \mathrm{L}$, bastonetes $130 \mu \mathrm{L}$, linfócitos $260,0 \mu \mathrm{L}$, monócitos $260,0 \mu \mathrm{L}$, eosinófilos $130,0 \mu \mathrm{L}$ e basófilos $0,0 \mu \mathrm{L}$. Na avaliação bioquímica, os valores encontrados foram: proteínas séricas totais $3,2 \mathrm{~g} / \mathrm{dL}$, albumina $2,3 \mathrm{~g} / \mathrm{dL}$ e globulina $0,9 \mathrm{~g} / \mathrm{dL}$, ureia $22,2 \mathrm{mg} / \mathrm{dL}$, fosfatase alcalina 157,0U/L e gamaglutamiltransferase 2,2U/L

A conduta médica adotada foi a realização da ovariossalpingo-histerectomia terapêutica (OSH), realizada no próprio Hospital. No précirúrgico, foi administrado o antiemético ondansetrona $(0,22 \mathrm{mg} / \mathrm{kg})$, o protetor gástrico ranitidina $(2 \mathrm{mg} / \mathrm{kg})$ e a fluidoterapia com vitaminas do complexo B e vitamina C. A anestesia foi geral inalatória. $\mathrm{O}$ protocolo anestésico adotado foi dividido em medicações pré-anestésicas (MPA), indução e manutenção. A MPA utilizada foi um opioide tramadol $(2 \mathrm{mg} / \mathrm{kg})$; para indução, usou-se propofol $(4 \mathrm{mg} / \mathrm{kg})$, e a manutenção anestésica foi feita com isoflurano vaporizado em oxigênio a $100 \%$, utilizando-se aparelho de anestesia inalatória em sistema respiratório. Foi feita anestesia local em espaço peridural com lidocaína a $2 \%$ $(0,25 \mathrm{~mL} / \mathrm{kg})$.

A OSH terapêutica foi realizada por meio da celiotomia mediana retroumbilical, quando, então, observou-se uma neoformação no ovário direito e no útero com presença de conteúdo. A seguir, fez-se uma janela no mesovário, caudal ao CAVO (complexo arteriovenoso ovariano), e pinçou-se o pedículo ovariano com três pinças hemostáticas (tipo crile). Posteriormente, foram feitas as ligaduras utilizando-se fio absorvível (categute cromado 2-0); em seguida, realizou-se a ressecção entre a primeira pinça mais ventral e a segunda. A mesma técnica foi utilizada para o corpo uterino, entretanto foi feita uma ligadura transfixada e com fio não absorvível monofilamentado (nylon 2-0). Depois, foi fechada a musculatura da parede abdominal, do tecido subcutâneo e da pele (Tudury et al., 2014). O pós-operatório foi mantido com antibioticoterapia prévia e foi prescrito uso de um antioxidante.

Amostras do ovário e do útero foram enviadas para o Laboratório de Patologia Veterinária para a realização do exame histopatológico (Fig. 4 e 5). As amostras foram fixadas em formol neutro, tamponado com fosfato a $10 \%$, e processadas pela técnica rotineira de inclusão em parafina. As secções histológicas foram coradas pelas técnicas da hematoxilina-eosina (Luna, 1968) 


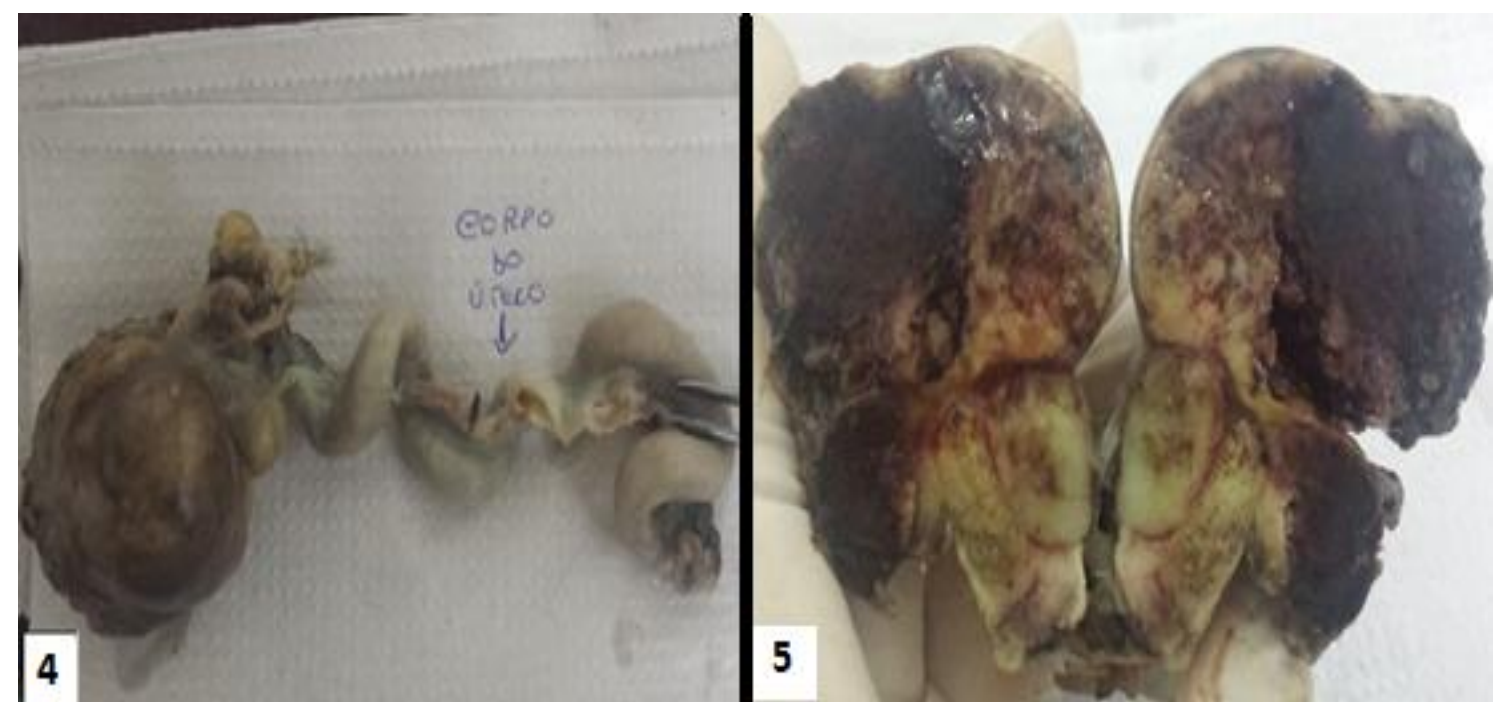

Figura 4. Ovário direito de uma gata de sete meses com tumor da célula da granulosa de superfície regular e útero com piometra. Figura 5. Ovário com tumor da célula da granulosa ao corte com superfície compacta com três formações circulares.

No retorno após 10 dias do procedimento cirúrgico, o proprietário relatou normodipsia, normúria e animal ativo. Ao exame físico, as mucosas estavam normocoradas, o animal encontrava-se hidratado, o tempo de preenchimento capilar era menor que dois segundos, a ausculta cardiopulmonar era limpa e clara, os linfonodos mostravam-se não reativos, a temperatura era de $38,9^{\circ} \mathrm{C}$ e a frequência cardíaca, de $160 \mathrm{bpm}$. A cicatriz cirúrgica se encontrava limpa e íntegra. Foi feita a retirada das suturas, e o paciente liberado.

No laudo histopatológico, observou-se macroscopicamente o útero medindo 18,0 centímetros de comprimento e o ovário direito aumentado, com dimensão de 4,1×3,0x3,9cm, superfície ovariana regular, coloração variando de branco-amarelada a enegrecida, consistência firme-elástica. Ao corte, constatou-se superfície compacta com três formações circulares de coloração vermelho-enegrecida, pardacenta e branco-amarelada; ovário contralateral sem alterações.

Na descrição microscópica, os cortes dos ovários em hematoxilina-eosina (HE) revelaram intensa e difusa infiltração de células neoplásicas semelhantes às células da granulosa, moderadamente pleomórficas, caracterizadas por serem pequenas e poliédricas, com escasso citoplasma eosinofílico, portando núcleos redondos e ovoides hipercromáticos, dispostas em arranjos foliculares envoltos por delicados septos conjuntivos (Fig. 6).

Em outras regiões, as células proliferantes mostraram-se grandes e poligonais, com citoplasma escasso a moderado, vacuolizado a eosinofílico, e núcleos predominantemente hipercorados ou mostrando cromatina finamente granular, redondos a ovoides, com nucléolos pouco visíveis; nesse aspecto, com aparência de células da teca ou granulosa luteinizadas.

O índice mitótico apresenta-se elevado, em média 10 mitoses por campo de maior aumento, atípicas. Em meio às células neoplásicas, há extensas áreas de necrose liquefativa com infiltração neutrofílica, intensa hemorragia, além de congestão vascular, bem como invasão de células neoplásicas em vasos linfáticos dilatados (êmbolos), o que evidencia o diagnóstico de célula da granulosa-teca (padrão sertoliforme) (Fig. 7). 


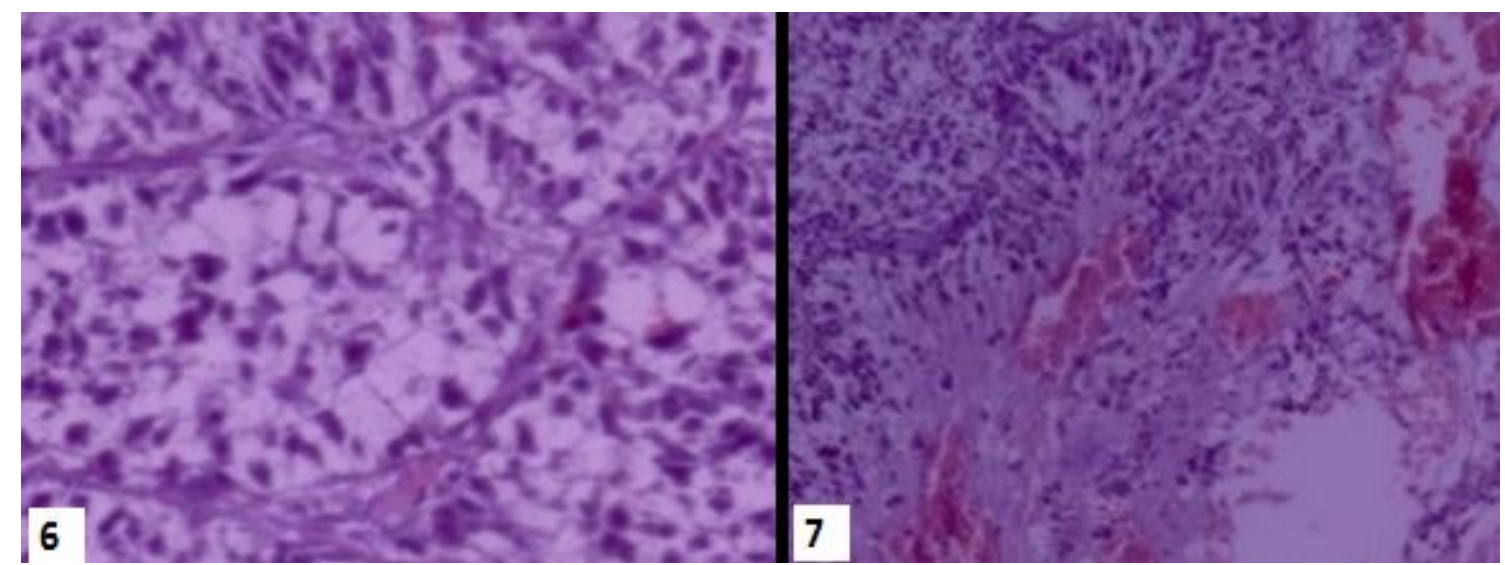

Figura 6. Secção microscópica do ovário de gata de sete meses com tumor da célula da granulosa, com células pleomórficas, pequenas e poliédricas dispostas em arranjos foliculares envoltos por delicados septos conjuntivos. Figura 7. Secção microscópica de ovário felino com TCG, com áreas de necrose liquefativa com infiltração neutrofílica, hemorragia.

Para o diagnóstico de piometra associada à hiperplasia endometrial cística, foram observadas secções de útero, coradas em H-E, o que evidencia mucosa endometrial fortemente delgada, desprovida de revestimento epitelial em diversas áreas, ou em esfoliação ou ainda em regeneração, portando glândulas endometriais atróficas ou dilatadas/císticas ou mesmo ausentes, ao lado de inúmeros focos de hemorragias; intensa exsudação celular de neutrófilos normais e degenerados (piócitos) no lúmen. Miométrio com plexo vascular intensamente dilatado, congesto e com leucocitoestase (Fig. 8 e 9).

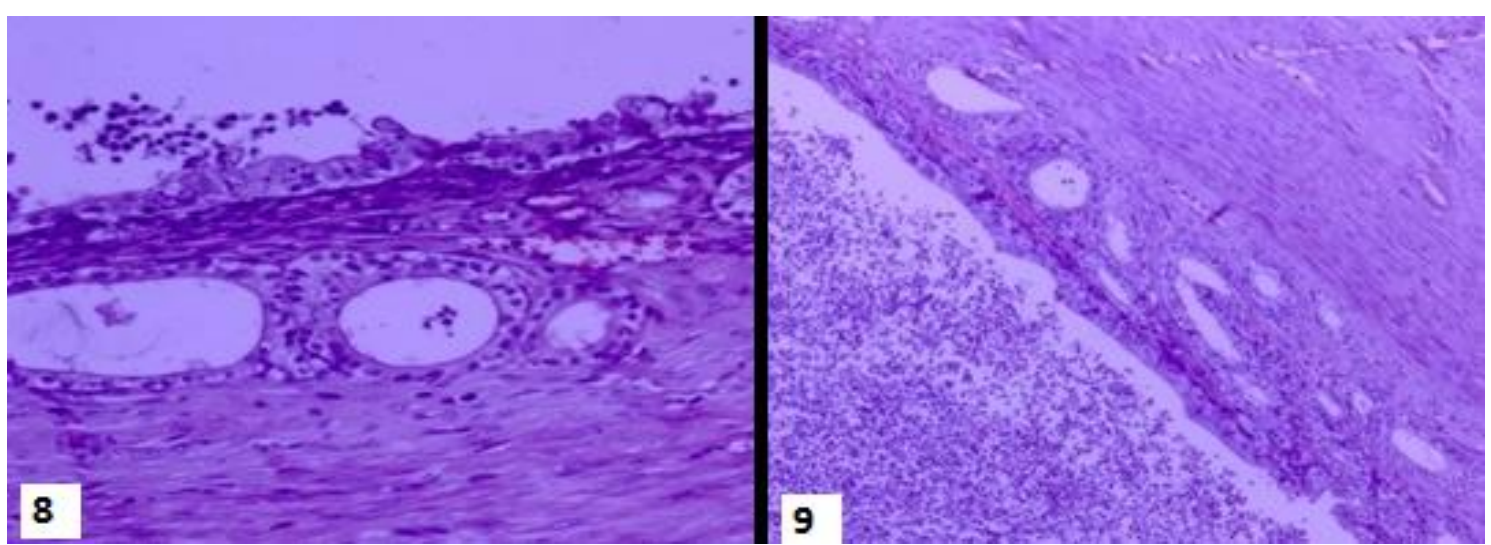

Figura 8. Secção microscópica de útero de gata de sete meses com piometra com mucosa endometrial delgada, desprovida de revestimento epitelial. Figura 9. Secção de útero felino com focos de hemorragias, intensa exsudação celular de neutrófilos normais e degenerados (piócitos) no lúmen.

\section{DISCUSSÃO}

Os sinais clínicos presentes em uma gata com tumor da célula da granulosa podem ser discretos. Quadros de sintomatologia equivalentes ao encontrado foram descritos por Souza et al. (2005), Daleck et al. (2009) e Scucato (2009), em relatos de TCG em gatas com sinais como corrimento vaginal sanguinolento, letargia, anorexia, aumento do volume abdominal, massa abdominal palpável, poliúria, êmese. Esses autores ainda relataram quadros de tumefação vulvar e estro persistente.

Perante uma neoplasia quanto ao risco de malignidade, o TCG em gatas, assim como em cadelas, segundo Daleck et al. (2009) e Scucato (2009), é maligno, e metástases podem ser evidenciadas nos linfonodos sublombares, no fígado, no pâncreas e nos pulmões. Nesses casos, 
o prognóstico é reservado, podendo cursar em óbito. Entretanto, não foram observados achados.

Apesar da possibilidade de metástase, o diagnóstico para TCG preciso e precoce pode não ser possível. Em exames complementares como a ultrassonografia, os achados não são precisos. Giacóia et al. (1999) descrevem que foi visibilizada uma formação ecogênica em região de ovário em uma gata de dois anos com TCG, o qual apresentava uma superfície regular, semelhante ao do presente estudo. Porém, Souza et al. (2005), ao apresentarem um caso de TCG, relataram a estrutura como sendo de superfície irregular e ainda com presença de cistos com conteúdo anecoico.

Quanto aos parâmetros sanguíneos descritos, a neutrofilia e a anemia norrmocítica e normocrômica, ambos achados encontrados, são esperadas em fêmeas com piometra, segundo Barni et al. (2013). Porém, em casos de TCG, quadros de pancitopenia podem ser evidenciados, visto que o desequilíbrio hormonal pode levar ao surgimento de síndrome paraneoplásica, devido à supressão da medula óssea, induzida pelo hiperestrogenismo (Daleck et al., 2009).

Essas alterações, entretanto, não foram observadas neste estudo, e tal fato é justificado, pois quadros de pancitopenia não são patognomônicos para neoplasia ovariana e podem estar ausentes (Giacóia et al., 1999; Souza et al., 2005; Daleck et al., 2009; Scucato, 2009). Nesse caso, o TCG acaba sendo um achado cirúrgico e o diagnóstico é fechado no exame histopatológico.

No exame histopatológico, a descrição macroscópica do presente trabalho está de acordo com relatos anteriores que citam ovários com TCG macroscopicamente aumentados de tamanho, firmes e geralmente unilaterais (Daleck et al., 2009). A superfície do tumor pode ser lisa ou irregular, ao corte sólido, cístico ou policístico, as partes sólidas variam de moles a firmes, a coloração também pode variar entre esbranquiçada, amarelada, laranja ou vermelha. É possível visualizar áreas de necrose e hemorragia (Santos e Alessi, 2011).

A descrição microscópica do TCG no exame histopatológico foi semelhante às descritas por Gelberg e Mcentee (1985), Giacóia et al. (1999) e Souza et al. (2005) apresentam células pequenas com núcleos arredondados, as quais podem exibir um padrão microfolicular (pequenas células poligonais dispostas em ninhos) ou sarcomatoso (células fusiformes dispostas em entrelaces ou cordões sarcomatosos difusos sustentados por estroma fino fibrovascular) e ainda com possibilidade de áreas de luteinização.

\section{CONCLUSÃO}

O tumor da célula da granulosa é uma neoplasia que pode cursar com manifestações clínicas discretas, as quais desencadeiam alterações hormonais que podem levar à ocorrência da HEC e evoluir para piometra. $\mathrm{O}$ exame ultrassonográfico fornece informações importantes para o diagnóstico presuntivo do tumor de células da granulosa, porém a confirmação se dá por meio de exame histopatológico.

\section{REFERÊNCIAS}

BARNI, B.S.; ALBUQUERQUE, P.B.; CONTESINI, E.A. Cystic endometrial hyperplasia in bitches and cats: review. Ciênc. Anim., v.23, p.9-19, 2013.

DALECK, C.R.; DE NARDI, A.B.; RODASKI, S. Neoplasias do sistema reprodutor feminino. In; . Oncologia em cães e gatos. São Paulo: Roca, 2009. cap.23, p.354-358.

GELBERG, H.B.; MCENTEE, K. Feline ovarian neoplasms. Vet. Pathol., v.22, p.572-576, 1985.

GIACÓIA, M.R.; MAIORKA, P.C.; OLIVEIRA, C.M. et al. Granulosa cell tumour with metastasis in a cat. Braz. J. Vet. Res.Anim. Sci., v.36, 1999. Available in: <http://www.scielo.br/scielo.php?pid=S141395961999000500005\&script=sci_arttext.> Accessed in 3 Mar. 2016.

LUNA L.G. Manual of histologic staining methods of the Armed Forces Institute of Pathology. New York: McGraw Hill, 1968. 258p.

MARTINS, D.G. Complexo hiperplasia endometrial cística/piometra em cadelas: fisiopatogenia, características clínicas, laboratoriais e abordagem terapêutica. 2007. 54f. Dissertação (Mestrado em Cirurgia Veterinária) - Faculdade de Ciências Agrárias e Veterinárias Câmpus de Jaboticabal, Universidade Estadual Paulista, SP. Disponível em: <http://repositorio.unesp.br/handle/11449/89044.> Acessado em: 3 mar 2016. 
SANTOS, R.L.; ALESSI, A.C. Sistema reprodutor feminino. In Patologia veterinária. São Paulo: Roca. 2011. cap.14, p.797-854.

SCUCATO, R.H., Tumor de célula da ganulosa com metástases abdominal e torácica - revisão de literatura e relato de caso. 2009. Monografia (Especialização em Clínica Médica e Cirúrgica em Pequenos Animais) UCB, Campinas, SP

SOUZA H.J.M.; AMORIM F.V.; JAFFÉ E. et al. Timoma e tumor de células da granulosa em gata. Acta Sci. Vet., v.33, p.211-217, 2005. Disponível em: <http://www.ufrgs.br/actavet/33-2/artigo629.pdf.> Acessado em: 3 mar. 2016.
SOUSA OLIVEIRA, K. Complexo hiperplasia endometrial cística. Acta Sci. Vet., v.35, Supl.2, p.s270-s272, 2007.

TUDURY, E.A. et al. Hemostasis and incision into the ovary pedicle of cats undergone elective ovariosalpingohysterectomy using the technique of the three bipolar forceps or eletrobisturi. Comparative study. Arq. Bras. Med. Vet. Zootec., v.66, p.14271434, 2014. 